\title{
Modification of pyruvate kinase and lactate dehydrogenase in foot muscle of the sea mussel Mytilus galloprovincialis under anaerobiosis and recovery
}

V.I. Lushchak ${ }^{1,2}$,

T.V. Bahnjukova ${ }^{1}$ and A.V. Spichenkov ${ }^{1}$

\author{
${ }^{1}$ Karadag Branch of Southern Sea Biology Institute, National Academy of \\ Sciences of Ukraine, p/s Kurortne, Feodosia, Crimea, 334876,Ukraine \\ ${ }^{2}$ Laboratório de Biofísica, Departamento de Biologia Celular, \\ Universidade de Brasília, 70910-900 Brasília, DF, Brasil
}

\section{Correspondence}

V.I. Lushchak

Karadag Branch of Southern Sea

Biology Institute

National Academy of Sciences

of Ukraine

$\mathrm{p} / \mathrm{s}$ Kurortne, Feodosia

Crimea, 334876

Ukraine

E-mail: lushchak@karadag.crimea.ua

Received May 17, 1996 Accepted January 15, 1997

\begin{abstract}
The modification of pyruvate kinase (PK) and lactate dehydrogenase (LDH) activity in foot muscle of the mussel Mytilus galloprovincialis during exposure to air and recovery in water was investigated. In the course of exposure to air, the activity of these enzymes measured at high and low substrate concentrations showed successive increases and decreases. Returning the mussels to water after exposure to air affected enzyme activity in a manner similar to anaerobiosis. When measuring at saturated concentrations of substrates and substrate and coenzyme for PK and LDH, respectively, the maximum activation of PK $(37 \%)$ was observed at $4 \mathrm{~h}$ of animal exposure to air, and for LDH (67\%) at $6 \mathrm{~h}$ exposure to air. During $24 \mathrm{~h}$ of exposure of animals to air, PK activity practically reached the stock level, while LDH was still activated (148\%). The change in lactate dehydrogenase activity in mussel muscle during anoxia and recovery is described here for the first time. Variation in pyruvate kinase activity during exposure to air and recovery is linked to the alteration of half-maximal saturation constants and maximal velocity for both substrates. The possible role of reversible phosphorylation in the regulation of pyruvate kinase and lactate dehydrogenase properties is discussed.
\end{abstract}

\section{Introduction}

Glycolysis is a major mechanism for energy production during anaerobiosis in different organs of the sea mussels Mytilus edulis and M. galloprovincialis. The terminal part of the glycolytic pathway in these mussels is modified for effective use of carbohydrate energy and solution of the end product problem. Usually phosphoenolpyruvate (PEP) is converted into pyruvate by pyruvate kinase (PK), but in mussel tissues it
Key words

- Mytilus galloprovincialis

- Muscle

- Anaerobiosis

- Pyruvate kinase

- Lactate dehydrogenase

- Property modification may also be converted into oxaloacetate by phosphoenolpyruvate carboxykinase (PEPCK) $(1,2)$. The oxaloacetate formed is reduced in mitochondria to malate and this reduction regulates a coenzyme redox balance in the cytoplasm. The regulation of this branchpoint is provided by the reversible phosphorylation of PK which in the muscles of mussel is an allosteric enzyme (3-5).

Pyruvate, the product of the PK reaction, can be converted into lactate by lactate dehydrogenase (LDH) or into octopine by octopine 
dehydrogenase (ODH). Since the activity of LDH in mussel tissues is rather low, under critical environmental conditions pyruvate is converted into octopine (6). Owing to this modification the end product of glycolysis, lactate, is not accumulated in tissues. The ratio of $\mathrm{LDH}$ and $\mathrm{ODH}$ activities regulates this branchpoint. The properties of $\mathrm{ODH}$ have been investigated (6), but those of LDH and the effect of environmental factors on this enzyme activity have not been studied.

Most of the work with mussels has been carried out on the common mussel M. edulis $(2,5,7)$, whereas the metabolism of $M$. galloprovincialis has been little investigated (8-10). The specific features of the Black Sea population of M. galloprovincialis are linked to the absence of a tide cycle; usually mussels are not exposed to air under natural conditions, but these mussels can survive out of water for a few days. The present report describes the modification of pyruvate kinase and lactate dehydrogenase activity during anaerobiosis and recovery of Mytilus galloprovincialis.

\section{Material and Methods}

All chemicals and biochemicals were purchased from Sigma Chemical (St. Louis, MO), and inorganic salts were from Reachim (USSR). Mussels, Mytilus galloprovincialis Lmk., 49-80 mm in shell length, weighing 7.3-27.9 g, were collected at Karadag Bay of the Black Sea (Crimea, Ukraine) in May 1995. The animals were kept in aquaria with flowing sea water at ambient temperature, $15-16^{\circ} \mathrm{C}$, without feeding for 1 day. Animals were exposed to air at the same temperature for $24 \mathrm{~h}$ and then replaced into water for 24 h (recovery). After exposure to air and recovery the foot muscle was rapidly dissected out and homogenized in 10 volumes $(\mathrm{g} / \mathrm{ml})$ of ice-cold buffer containing $20 \mathrm{mM}$ imidazole- $\mathrm{HCl}, \mathrm{pH} 7.0,100 \mathrm{mM} \mathrm{KCl}, 1 \mathrm{mM}$ dithiothreitol, $20 \mathrm{mM} \mathrm{KF}$, and $1 \mathrm{mM}$ ethylenediaminetetraacetic acid (EDTA) in a Pot- ter glass homogenizer. Before homogenization a few crystals of the protease inhibitor phenylmethylsulfonyl fluoride (PMSF) were added to the homogenate. Homogenate aliquots were centrifuged at $45,000 \mathrm{~g}$ for 15 $\min$ at $4^{\circ} \mathrm{C}$. The supernatant was used for measurement of enzyme activity after overnight dialysis with 100 volumes of the homogenization buffer.

The activity of PK was measured by an assay coupled with LDH. Change of light absorption as the result of NADH oxidation by LDH was monitored at $340 \mathrm{~nm}$ using an SF-46 spectrophotometer (LOMO, Leningrad, USSR) at $25^{\circ} \mathrm{C}$. The reaction medium for PK activity determination contained 50 $\mathrm{mM}$ imidazole- $\mathrm{HCl}$ buffer, $\mathrm{pH}$ 7.0, $10 \mathrm{mM}$ $\mathrm{MgCl}_{2}, 100 \mathrm{mM} \mathrm{KCl}, 2 \mathrm{mM}$ ADP, $1 \mathrm{mM}$ PEP, $160 \mu \mathrm{MNADH}$, excess of LDH, and 5$10 \mu \mathrm{l}$ of the supernatant. The reaction medium for LDH activity contained $20 \mathrm{mM}$ imidazole-HCl buffer, $\mathrm{pH}$ 7.5, 1 mM EDTA, 160 $\mu \mathrm{M}$ NADH, $1 \mathrm{mM}$ pyruvate and $20 \mu \mathrm{l}$ of the supernatant. Both reactions were started by the addition of the homogenate. One unit of enzyme activity is the amount of enzyme that converts $1 \mu \mathrm{mol}$ of substrate per $1 \mathrm{~min}$ at $25^{\circ} \mathrm{C}$ (IU).

Kinetic parameters of enzymes were calculated using a special kinetic program (11) with an IBM PC/AT-286 personal computer. All values are reported as means \pm SEM. Differences between means were estimated by the one-tailed Student $t$-test.

\section{Results}

\section{Pyruvate kinase}

Figure 1 shows the effect of exposure to air and recovery on the activity of PK from mussel foot muscle measured at saturating concentrations of both substrates (curve 1), and at a saturating concentration of ADP and a low concentration of PEP (curve 2). The shape of the PK activity curve measured in the presence of $0.2 \mathrm{mM}$ ADP and $1 \mathrm{mM}$ PEP 
was similar to that found at low PEP concentration (data not shown). Returning the mussels to sea water saturated with oxygen (to $100 \%$ ) led to further activation followed by enzyme inactivation.

The kinetic properties of PK from mussel foot muscle exposed to different conditions are shown in Table 1. The maximal activity $\left(\mathrm{V}_{\max }\right)$ increased during the experimental procedure and this agrees well with the data illustrated in Figure 1. The half-maximal activation constant $\left(\mathrm{S}_{0.5}\right)$ of PK by PEP decreased, while for ADP this value increased. Anaerobiosis and recovery strongly affected $\mathrm{S}_{0.5}$ for ADP up to $48 \mathrm{~h}$ of experiment. This variable increased 3.5-fold over this time. Another interesting aspect was the decrease of Hill coefficients $\left(\mathrm{n}_{\mathrm{H}}\right)$ for both substrates after the start of the experiment (Table 1).

\section{Lactate dehydrogenase}

Figure 2 shows the variation of $\mathrm{LDH}$ activity in mussel foot muscle measured at saturating concentrations of both pyruvate and NADH (curve 1), and at low pyruvate concentration $(0.2 \mathrm{mM})$ with saturation by the coenzyme (curve 2). The shape of the LDH activity curve measured at low NADH concentration and high substrate concentration was similar to curve 2 of Figure 2 (data not shown). LDH activity increased during 6 $\mathrm{h}$ of anaerobiosis and decreased on further exposure to air. The shape of the LDH activation and inhibition curves for exposure to air was closely similar to that of PK. However, returning the mussels to water produced an activation of LDH which was pronounced up to $48 \mathrm{~h}$ of experiment, i.e., up to $24 \mathrm{~h}$ after their return to water.

\section{Discussion}

PK and LDH activities in foot muscle of M. galloprovincialis were close to those of M. edulis (7), and those found earlier for $M$. galloprovincialis (8). PK activity was about

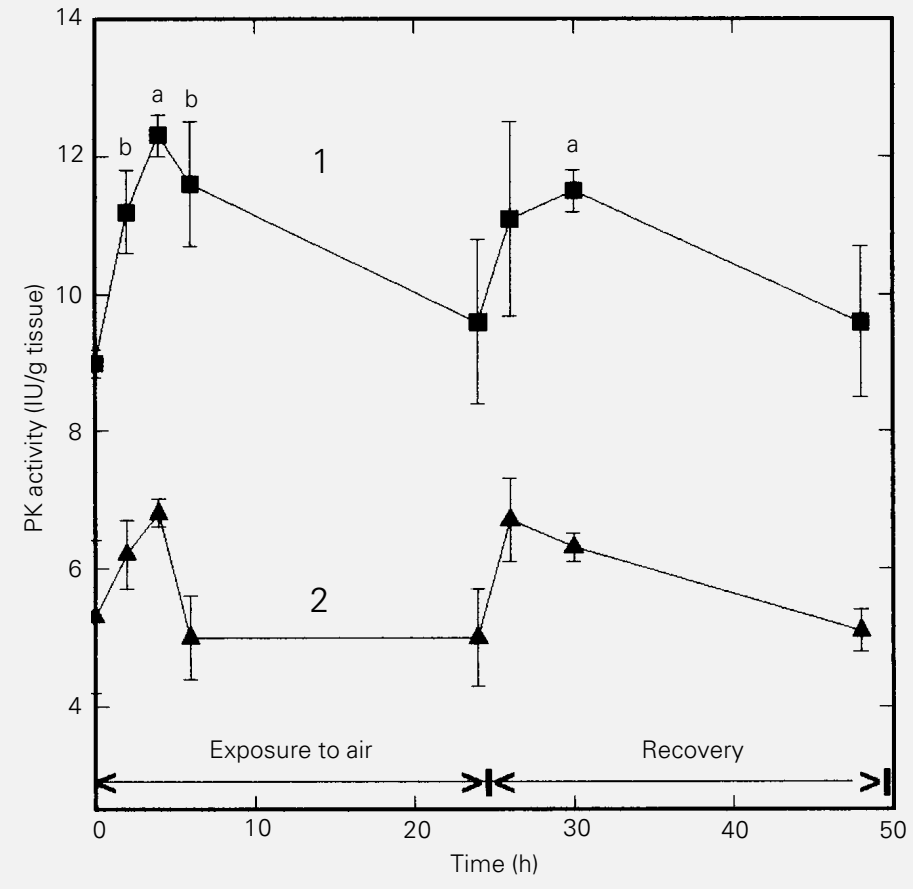

Figure 1 - Effect of exposure to air and recovery on pyruvate kinase (PK) activity measured at saturating substrate concentrations $(1 \mathrm{mM}$ phosphoenolpyruvate and $2 \mathrm{mM}$ ADP, curve 1) and low phosphoenolpyruvate concentration $(0.15 \mathrm{mM}$, curve 2). Data are reported as means \pm SEM for four individuals. Significantly different from "zero" time with ${ }^{\mathrm{a}} \mathrm{P}<0.001$ and $\mathrm{b} \mathrm{P}<0.025$.

Table 1 - Kinetic properties of pyruvate kinase from mussel foot muscle.

Data are reported as means \pm SEM $(N=4)$. So.5: Half-maximal activation constant; $\mathrm{nH}_{\mathrm{H}}$ : Hill coefficients; $\mathrm{V}_{\text {max: }}$ maximal activity. ${ }^{\mathrm{a} P}<0.05$, ${ }^{\mathrm{b}} \mathrm{P}<0.005$, ${ }^{\mathrm{c}} \mathrm{P}<0.001$ compared to control group (Student $t$-test).

\begin{tabular}{llccc}
\hline Substrate & Conditions & $\mathrm{S}_{0.5}(\mathrm{mM})$ & $\mathrm{n}_{\mathrm{H}}$ & $\mathrm{V}_{\max }$ (units/g tissue) \\
\hline PEP & Control & $0.21 \pm 0.05$ & $1.18 \pm 0.14$ & $12.7 \pm 1.0$ \\
& Anoxia (h) & & & \\
3 & $0.16 \pm 0.02$ & $0.86 \pm 0.07$ & $15.7 \pm 0.2^{\mathrm{a}}$ \\
6 & $0.13 \pm 0.03$ & $0.91 \pm 0.06$ & $12.9 \pm 0.8$ \\
24 & $0.18 \pm 0.01$ & $1.19 \pm 0.07$ & $15.7 \pm 1.4$ \\
& & & \\
& Recovery (h) & & & \\
3 & $0.20 \pm 0.04$ & $0.89 \pm 0.17$ & $14.0 \pm 0.9$ \\
6 & $0.10 \pm 0.02$ & $0.97 \pm 0.15$ & $13.4 \pm 0.8$ \\
& 24 & $0.23 \pm 0.05$ & $0.84 \pm 0.11$ & $15.4 \pm 0.7$ \\
ADP & & & \\
& Control & $0.28 \pm 0.08$ & $1.32 \pm 0.19$ & $13.6 \pm 0.9$ \\
& Anoxia (h) & & & \\
3 & $0.51 \pm 0.14$ & $1.09 \pm 0.26$ & $16.3 \pm 1.9$ \\
6 & $0.56 \pm 0.14$ & $0.80 \pm 0.87 \mathrm{a}$ & $16.6 \pm 1.8$ \\
24 & $0.40 \pm 0.03$ & $0.88 \pm 0.05$ & $15.4 \pm 0.6$ \\
& & & \\
Recovery (h) & & & \\
3 & $0.38 \pm 0.06$ & $0.99 \pm 0.16$ & $14.2 \pm 1.0$ \\
6 & $0.36 \pm 0.05$ & $0.92 \pm 0.11$ & $14.6 \pm 1.6$ \\
24 & $0.98 \pm 0.09 \mathrm{~b}$ & $0.77 \pm 0.03^{\mathrm{a}}$ & $20.8 \pm 0.5 \mathrm{c}$
\end{tabular}




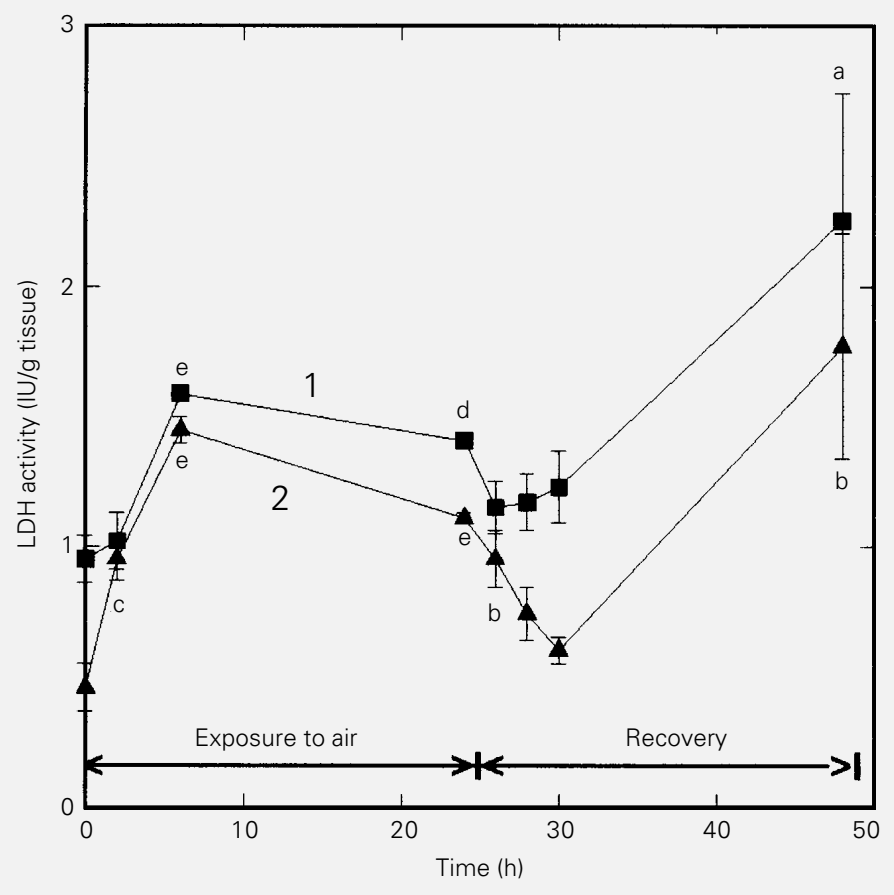

Figure 2 - Effect of exposure to air and recovery on lactate dehydrogenase (LDH) activity measured at saturating concentrations (1 mM pyruvate and $160 \mu \mathrm{M}$ $\mathrm{NADH}$, curve 1) and low pyruvate concentration (0.2 mM pyruvate and $160 \mu \mathrm{M}$ $\mathrm{NADH}$, curve 2). Data are reported as means \pm SEM for four individuals. Significantly different from "zero" time with ${ }^{\mathrm{a} P}<0.05, \quad{ }^{\mathrm{b}} \mathrm{P}<0.025, \quad{ }^{\mathrm{C}}<<0.01$, $\mathrm{d} P<0.005$, and ${ }^{\mathrm{e}} \mathrm{P}<0.001$, respectively.

10-fold higher than that of LDH. The ratio of PK and LDH activities, combined with the presence of high ODH activity in mussel tissues, provides a species-specific possibility of glycolytic pathway regulation. The in vivo balance between the uses of pyruvate under anoxic conditions is determined by the ratio of $\mathrm{LDH}$ and $\mathrm{ODH}$ activities as well as the availability of substrates for both enzymes, i.e., their distribution in the cell volume.

Exposure to air first activated PK and $\mathrm{LDH}$, followed by a decrease in their activities after $6 \mathrm{~h}$ of exposure. This reversible process shows two phases of reaction of the mussel organism under these conditions. The first phase is a stress reaction and may be linked to the activation of glycolysis. The second phase represents adaptation to anaerobiosis. Exposure to air increased $\mathrm{V}_{\max }$ and decreased $S_{0.5}$ for PEP and increased this variable for ADP (Table 1). Since $n_{H}$ for both substrates was decreased, we may conclude that the interaction between the active sites in the PK oligomer is changed.

Upon recovery, the pattern of PK activity changes was similar to that observed upon exposure to air, which means that the restoration of normal conditions is also a stress for mussels. However, the curve for LDH activity was different and showed activation of the enzyme up to the 48th $\mathrm{h}$ of the experiment. It may be supposed that the regulation mechanisms of LDH and PK activities are different.

These data agree well with the effect of anoxia and recovery on the energy metabolism of M. edulis and M. galloprovincialis. Concentrations of ATP, ADP, phospho-arginine (functional analogue of phosphocreatine in molluscs), inorganic phosphate and $\mathrm{pH}$ in their muscle were changed under these conditions $(8,12,13)$.

When PK and LDH activities were measured at low concentrations of one of the substrates, the effect of exposure to air and recovery was found to be quite similar to that measured at saturating substrate concentrations (Figures 1 and 2). An analogous method was recently described for glycolytic enzymes from M. edulis tissues (14).

Activation of PK during the first period of exposure to air was described by Holwerda and colleagues (3) for the enzyme from adductor muscle of M. edulis. However, PK activity had decreased by the 4 th $h$ of anaerobiosis and reached approximately its initial level after 8 h. At first cAMP and cGMP levels decreased but were restored at $4.5 \mathrm{~h}$ of anaerobiosis (3). The correlation of PK activity and the level of cyclic nucleotides raised the idea of the possible participation of reversible phosphorylation in the regulation of enzyme activity which was indeed reported later (4). The non-phosphorylated PK form was characterized by a lower apparent $\mathrm{K}_{\mathrm{m}}$ for PEP. In our case, exposure to air decreased the affinity of PK for PEP, but the effect on enzyme activity was similar to that described for M. edulis. Additionally, we found a decrease in the affinity for 
ADP (increase of $\mathrm{S}_{0.5}$ ). On the basis of these data, it may be supposed that the change of PK activity during anaerobiosis and recovery is linked to the reversible phosphorylation processes. This mechanism of PK modification was found to be due to the effect of environmental hypoxia on the organism of the mollusc Patella caerulea (15), the worm Phascolosoma arcuatum (16), and the land snailOtala lactea (17). Although muscle PK is not a regulatory enzyme in vertebrates (18), in invertebrates this enzyme is regulatory and is analogous to its liver form from vertebrates (35,15-17).

Two differentmechanisms may beinvolved in the regulation of LDH activity under these experimental conditions. The first may be re- versible phosphorylation and the second gene expression. Although it is widely accepted that LDH cannot be reversibly phosphorylated by protein kinases, there is at least one piece of direct evidence for this process in vivo in chicken fibroblast cells transformed by Rous sarcoma virus (19). Therefore, it cannot be ruled out that the reversible phosphorylation of $\mathrm{LDH}$ regulates the terminal part of the glycolytic pathway in mussels, but this idea requires special investigation.

\section{Acknowledgment}

The authors thank Mr. Scott Brogan for correcting the English text.

\section{References}

1. Hochachka PW, Fields JA \& Mommsen TP (1983). Metabolic and enzyme regulation during rest-to-work transition: A mammal vs mollusc comparison. In: Hochachka PW (Editor), The Mollusca. 1st edn. Academic Press, New York, 56-89.

2. Zwaan De A (1983). Carbohydrate metabolism in bivalves. In: Hochahcka PW (Editor), The Mollusca. 1st edn. Academic Press, New York, 138-175.

3. Holwerda DA, Kruitwagen ECJ \& Bont AM (1981). Regulation of pyruvate kinase and phosphoenolpyruvate carboxykinase activity during anaerobiosis in Mytilus edulis L. Molecular Physiology, 1: 165171.

4. Holwerda DA, Veenhof PR, Heugten HAA \& Zandee DI (1983). Modification of mussel pyruvate kinase during anaerobiosis and after temperature acclimation. Molecular Physiology, 3: 225-234.

5. Holwerda DA, Veldhuixen-Tsoerkan M, Veenhof PR \& Evers E (1989). In vivo and in vitro studies on the pathway of modification of mussel pyruvate kinase. Comparative Biochemistry and Physiology, 92B: 375-380

6. Storey KB \& Storey JM (1983). Carbohydrate metabolism in cephalopods. In: Hochachka PW (Editor), The Mollusca. 1st edn. Academic Press, New York, 92-136.
7. Storey KB \& Dando PR (1982). Substrate specificities of octopine dehydrogenases from marine invertebrates. Comparative Biochemistry and Physiology, 73B: 521528.

8. Goromosova SA \& Shapiro AZ (1984). The Main Features of Biochemistry of Mussels Energetical Metabolism. Light and Food Industry, Moscow.

9. Ibarguren I, Vazquez-IIlanes MD \& RamosMartinez JI (1990). Seasonal variations in glycolysis in Mytilus galloprovincialis Lmk. Comparative Biochemistry and Physiology, 97B: 279-283.

10. Villamarin JA \& Ramos-Martinez JI (1990). Kinetic studies on the reaction catalyzed by phosphofructokinase from Mytilus galloprovincialis (Lamarck). Comparative Biochemistry and Physiology, 95B: 531534.

11. Brooks SPJ (1992). A simple computer program with statistical tests for the analysis of enzyme kinetics. Biotechniques, 213: 906-911.

12. Schanck A, Verbaert $B$, Van Meersche $M$, Baguet F \& Devroede J (1986). ${ }^{31} \mathrm{P}$ nuclear-magnetic-resonance study of muscles from Mytilus edulis. European Journal of Biochemistry, 156: 625-629.

13. Fan TW-M, Higashi RM \& MacDonald JM (1991). Emergence and recovery response of phosphate metabolites and intracellular $\mathrm{pH}$ in intact Mytilus edulis as examined in situ by in vivo ${ }^{31}$ P-NMR. Biochimica et Biophysica Acta, 1092: 39-47.
14. Churchill HM \& Livingstone DR (1989). Kinetic studies of the glycolytic enzymes from the mantle and posterior adductor muscle of the common mussel, Mytilus edulis L., and use of activity ratio $\left(V_{m} / v\right)$ as an indicator of apparent $\mathrm{K}_{\mathrm{m}}$. Comparative Biochemistry and Physiology, 94B: 299314.

15. Michaelidis B, Gaitanaki C \& Beis IS (1988). Modification of pyruvate kinase from the foot muscle of Patella caerulea (L.) during anaerobiosis. Journal of Experimental Zoology, 248: 264-271.

16. Lim RWL \& Ip YK (1991). Alteration of kinetic properties of pyruvate kinase in Phascolosoma arcuatum (Sipunculida) exposed to environmental anoxia. Journal of Experimental Marine Biology and Ecology, 152: 123-133

17. Whitwam RE \& Storey KB (1990). Pyruvate kinase from the land snail Otala lactea: regulation by reversible phosphorylation during estivation and anoxia. Journal of Experimental Biology, 154: 321-337.

18. Hsu YC, Bloxham DP \& Giles IG (1987) Phosphorylation of type-L pyruvate kinase in intact hepatocytes. Localization of the phosphorylation site in response to both glucagon and the $\mathrm{Ca}^{2+-}$ linked agonist phenylephrine. FEBS Letters, 218: 1-6.

19. Cooper JA, Reiss NA, Schwartz RJ \& Hunter T (1983). Three glycolytic enzymes are phosphorylated at tyrosine in cells transformed by Rous sarcoma virus. $\mathrm{Na}$ ture, 302: 218-223. 